\title{
BMJ Open Understanding what women want: eliciting preference for delivery health facility in a rural subcounty in Kenya, a discrete choice experiment
}

\author{
Jackline Oluoch-Aridi (D) , ${ }^{1,2}$ Mary B Adam, ${ }^{3}$ Francis Wafula, ${ }^{1}$ Gilbert Kokwaro ${ }^{1}$
}

To cite: Oluoch-Aridi J, Adam MB, Wafula F, et al. Understanding what women want: eliciting preference for delivery health facility in a rural subcounty in Kenya, a discrete choice experiment. BMJ Open 2020;10:e038865. doi:10.1136/ bmjopen-2020-038865

- Prepublication history and additional material for this paper are available online. To view these files, please visit the journal online (http://dx.doi. org/10.1136/bmjopen-2017018243).

Received 27 March 2020 Revised 13 October 2020 Accepted 24 October 2020

Check for updates

(c) Author(s) (or their employer(s)) 2020. Re-use permitted under CC BY-NC. No commercial re-use. See rights and permissions. Published by BMJ.

${ }^{1}$ Institute of Healthcare Management, Strathmore University Business School, Strathmore University, Nairobi, Kenya

${ }^{2}$ Ford Family Program in Human Development Studies and Solidarity, Kellogg Institute of International Studies, University of Notre Dame, Nairobi, Kenya ${ }^{3}$ Pediatrics and Community Health, Kijabe Hospital, Kijabe, Kiambu, Kenya

Correspondence to Jackline Oluoch-Aridi; joluocha@nd.edu

\section{ABSTRACT}

Objective To identify what women want in a delivery health facility and how they rank the attributes that influence the choice of a place of delivery.

Design A discrete choice experiment (DCE) was conducted to elicit rural women's preferences for choice of delivery health facility. Data were analysed using a conditional logit model to evaluate the relative importance of the selected attributes. A mixed multinomial model evaluated how interactions with sociodemographic variables influence the choice of the selected attributes. Setting Six health facilities in a rural subcounty. Participants Women aged 18-49 years who had delivered within 6 weeks

Primary outcome The DCE required women to select from hypothetical health facility A or B or opt-out alternative.

Results A total of 474 participants were sampled, 466 participants completed the survey (response rate $98 \%$ ). The attribute with the strongest association with health facility preference was having a kind and supportive healthcare worker $(\beta=1.184, p<0.001)$, second availability of medical equipment and drug supplies $(\beta=1.073$, $p<0.001)$ and third quality of clinical services $(\beta=0.826$, $\mathrm{p}<0.001)$. Distance, availability of referral services and costs were ranked fourth, fifth and sixth, respectively $(\beta=0.457, p<0.001 ; \beta=0.266, p<0.001 ;$ and $\beta=0.000018$, $p<0.001)$. The opt-out alternative ranked last suggesting a disutility for home delivery $(\beta=-0.849, p<0.001)$. Conclusion The most highly valued attribute was a process indicator of quality of care followed by technical indicators. Policymakers need to consider women's preferences to inform strategies that are person centred and lead to improvements in quality of care during delivery.

\section{BACKGROUND}

In 2017, an estimated 295000 women died while giving birth. While this represents a $35 \%$ improvement from 451000 maternal deaths in 2000, the vast majority of these deaths are preventable. ${ }^{1}$ Strategies to reduce the high burden of maternal mortality in low and middle-income countries have included increasing coverage for high-quality facilitybased delivery. ${ }^{2}{ }^{3}$ Facility-based delivery is
Strengths and limitations of this study

- The study was done under the context of the free maternity services policy in Kenya and will inform the contextual aspects of quality of care valued by women based on their experience of care during delivery.

- The study provided a ranking of the attributes of health facility delivery valued by women in a rural setting that can be useful to policymakers when prioritising resources for quality of care improvements.

- The hypothetical nature might result in bias as respondents might make aspirational choices regarding the attributes rather than choices that represent their preferences.

- Hypothetical choices might not be representative of women's choices because decision-making around delivery place in real life may be made in a social context with other key family members involved especially in rural contexts.

increasing in sub-Saharan Africa due to the growing attention to efforts to reduce maternal mortality resulting in substantial declines in mortality over the last few decades. ${ }^{45}$ This has been facilitated in part by overcoming barriers to access such as cost and distance. However, there remains the challenge of growing inequities in maternal health outcomes within countries and this demands that we pay attention to the barriers to access to high-quality facility-based delivery.

Kenya is one of the countries exhibiting insufficient progress in reducing preventable maternal deaths, the reported maternal mortality ratio is currently estimated at 362 deaths per 100000 live births. ${ }^{6}$ In a major move to eliminate barriers such as cost, the government initiated the free delivery policy in 2013. ${ }^{7}$ The government's free maternity policy together with access to private delivery care financed by the National Health Insurance Fund expanded the options for delivery health facilities available for women to choose 
from. This resulted in positive trends in access to facilitybased delivery particularly in rural areas where investments in the health system and physical infrastructure such as road network had resulted in increased access. The total numbers of healthcare facilities in Kenya have grown to 3965 over the last 10 years. ${ }^{8}$ All these strategies increased women's choices available for delivery health facilities.

However, inequities in maternal health outcomes still exist in Kenya particularly at the county level. A recent United Nations Population Fund (UNFPA) report in Kenya identified 15 counties that contribute to $98.7 \%$ of the maternal deaths with most of the deaths in rural counties. ${ }^{9}$ The quality of care provided also differs substantively across regions in Kenya with one study identifying a 25-percentage point gap between Nairobi and Coast regions. ${ }^{10}$ Additionally, higher volume facilities and those with caesarean section capacity seemed to offer a high quality of care. ${ }^{10}$ There have also been recent reports of increased utilisation of county-level (referral) hospitals for deliveries. ${ }^{11}$ National assessments of quality of care at health facilities in Kenya suggest that poorer women have a higher likelihood of encountering poor quality of maternal health services in Kenya. ${ }^{12}{ }^{13}$ Assessments targeting primary health facilities have shown that these facilities offer poorer quality of services, with gaps with regard to basic infrastructure, medical equipment and supplies, a diagnostic accuracy and adherence to clinical guidelines. ${ }^{14}{ }^{15}$ Within this context there is significant overlap between primary health facilities and delivery health facilities. With the free maternity services policy, health centres and dispensaries at the primary level of care were upgraded in order to be able to provide uncomplicated childbirth services. The government in recent times introduced the Kenya Quality Model for Health to improve the quality of care at health facilities. ${ }^{16}$ This strategy aimed to support quality improvement by providing minimum standards and guidelines, and support the structure-process-outcome of health services by applying the principles and tools of quality management. However, several implementation challenges were identified such as substandard structures at health facilities and lack of pharmaceutical supplies at health facilities.

The WHO framework on quality of health services during facility-based delivery proposes that a high-quality health system is safe, effective, patient centred, timely, efficient and equitable. ${ }^{17}$ These frameworks assume knowledge of the end users. However, it is likely that Kenyan women in rural areas may be incapable of assessing the clinical quality from a technical standpoint. They are able to assess the quality of the care and choose delivery health facilities based on their experience of care such as respectful treatment by healthcare workers. They are also able to assess other aspects of provision of care, such as the availability of medical equipment like theatre for caesarean section during an emergency, accessing drug supplies within the facility versus an outside pharmacy and referral services that include transportation to a higher level facility.

There is limited knowledge in Kenya on the specific elements women value most in the care they receive from the health facilities. Most strategies available for assessing quality of care received during childbirth in Kenya have focused only on either the health system inputs required or satisfaction levels at the end of the continuum of care. Strategies are also based on national-level assessments of quality of care such as service provision assessment and demographic health surveys. ${ }^{68}$ These studies, while useful and nationally representative, fail to identify and provide a ranking for demand side barriers. As a consequence, national data at present are unable to fully explain why women prefer certain health facilities over others. Contextual information on what women value when making decisions on choice of a health facility becomes increasingly important as women's choices increase. This information is particularly useful in resource-constrained settings where prioritisation guides allocation of scarce health resources.

Discrete choice experiments (DCE) can be particularly helpful in eliciting preferences. DCEs allow health services users to state individual preferences when offered different hypothetical choices. ${ }^{18}$ They are based on the assumption that services can be described by their attributes, and that the value of a service depends on the nature and level of these attributes. ${ }^{19}$ DCEs have been used to examine a broad range of health system challenges in sub-Saharan Africa including patient preferences for hospital services in South Africa ${ }^{20}$ and maternal health services in rural areas of Ethiopia and Tanzania. ${ }^{2122}$ The main objective of this study was to use a DCE to elicit women's preferences with regard to the characteristics of a delivery health facility based on their delivery experiences in a rural subcounty. We aim to provide insights on what a woman's view of quality of care is, based on their experience of care. We hope these preferences will present the patient perspective to complement the needed technical quality improvement to support the development of a quality health system, so women can get what they want and deserve from the health system.

\section{METHODS \\ Study setting}

Naivasha Sub-County is a semirural setting $50 \mathrm{~km}$ northwest of Nairobi. It is composed of periurban settlements, and includes agriculturalist and pastoralist populations within Nakuru County. It has a population of roughly 181966 people. Primary and secondary health facilities include government health facilities, several private health facilities and Naivasha County Referral Hospital. The population is also served by a faith-based private tertiary hospital, about $20 \mathrm{~km}$ away from Naivasha in neighbouring Kiambu County. Naivasha was selected as a study site because recent evidence from a UNFPA 
Table 1 Final list of attributes and attribute levels included for the DCE

\begin{tabular}{|c|c|}
\hline Attribute & Attribute level \\
\hline \multirow{2}{*}{$\begin{array}{l}\text { Quality of clinical services at } \\
\text { the health facility }\end{array}$} & Good quality services \\
\hline & Bad quality services \\
\hline \multirow[t]{2}{*}{ Attitude of healthcare workers } & $\begin{array}{l}\text { Kind and supportive } \\
\text { healthcare worker }\end{array}$ \\
\hline & $\begin{array}{l}\text { Unkind and unsupportive } \\
\text { healthcare worker }\end{array}$ \\
\hline \multirow[t]{2}{*}{$\begin{array}{l}\text { Availability of medical } \\
\text { equipment and supplies }\end{array}$} & $\begin{array}{l}\text { Medical equipment and } \\
\text { supplies available }\end{array}$ \\
\hline & $\begin{array}{l}\text { Medical equipment and } \\
\text { supplies not available }\end{array}$ \\
\hline \multirow[t]{2}{*}{ Distance to the health facility } & $\begin{array}{l}\text { Health facility is close to } \\
\text { residence }\end{array}$ \\
\hline & $\begin{array}{l}\text { Health facility is far from } \\
\text { residence }\end{array}$ \\
\hline \multirow[t]{2}{*}{ Referral at the health facility } & $\begin{array}{l}\text { Referral services available at } \\
\text { the health facility }\end{array}$ \\
\hline & $\begin{array}{l}\text { Referral services unavailable } \\
\text { at the health facility }\end{array}$ \\
\hline Cost of delivery service (Ksh) & $3000 ; 5000 ; 8000$ \\
\hline
\end{tabular}

DCE, discrete choice experiment; Ksh, Kenyan shilling.

report rank ordered counties by contribution to the burden of maternal deaths and Nakuru County was ranked fourth. ${ }^{9}$

\section{Discrete choice experiments}

Identification of attributes and attribute levels

DCEs are an attribute driven technique used to elicit stated preferences and interventions and are based on the assumption that healthcare intervention services and policies can be described by their attributes. ${ }^{18}$ The first stage in the development of a DCE is the identification of attributes and attribute levels. Previous studies suggest a review of the literature and qualitative work to aid in the identification of relevant attributes. ${ }^{23}$ We undertook a comprehensive literature review on the topic of facility-based delivery and skilled birth attendance in subSaharan Africa to gain an in-depth understanding of the factors influencing place of delivery. We also conducted a qualitative study with six focus group discussions with 50 women at a mix of public and private health facilities. We also conducted in-depth interviews with 12 healthcare workers serving as in-charges at the maternities. We used an interview guide (see online supplemental appendix 1). The participants were purposively selected women aged 18-49 and had just delivered their babies within 6 weeks and were attending child welfare clinics at the different health facilities. Table 1 shows the final attributes and attribute levels selected for the DCE.

\section{Experimental design}

The attributes of the interventions and their assigned levels were combined using experimental designs that produce a set of hypothetical choice alternatives. Respondents were asked to choose which alternatives they prefer the attribute levels determine the utility of respondents attached to a particular characteristic of an intervention and hence their preferences. ${ }^{24}$ The DCE was designed as an unlabelled one with 16 choice sets presented under three alternatives: health facility A, health facility B and an opt-out alternative where the woman would choose none of the two facilities, presented as preference for home delivery. See table 1 for the final attributes and attribute levels included in the DCE. All attributes in the choice experiment had two levels each except cost, which had three levels. This resulted in a design of $\left(2^{5} \times 3^{1}=96\right)$ choices in the full fractional design. This number of choices would have been too tedious for the respondents to handle. We opted to use a fractional factorial design to reduce the choices from 36 to 16 , making it manageable for the respondents. This was done using a D-efficient design using Ngene software to generate the original experimental design ${ }^{25}$ (see online supplemental appendix 2). All the attributes were dummy coded to allow comparison against a reference category. The reference categories were those that were the dominant choice, for example, good quality of clinical services, kind and supportive healthcare workers, availability of medical equipment, availability of referral services, short distance to the health facility and the lowest price of delivery service (Ksh3000). The D-efficient design also allowed for favourable design such as orthogonality, level balance, minimum balance and overlap. ${ }^{26}$ The 16 choice set questions were generated from the design. Each choice set contained 16 questions. We then divided each choice set into two sets with eight questions each, and each respondent was presented with a single choice set from a single block.

\section{DCE study sample}

The choice sets were reviewed for content by a team of policymakers from the county headquarters during a 1-day meeting at the main referral hospital at the county. The meeting confirmed and validated the choice of attributes as important to both women and healthcare workers. This was followed by a pilot study with 30 women in a neighbouring subcounty to test the attributes. The women who participated in the pilot were not included in the main study. The pilot resulted in minor revisions to the wording of certain attributes, for example, the attribute 'treatment at the health facility' was changed to 'quality of clinical care during delivery' to provide a distinction between interpersonal and clinical aspects of quality of care. The availability of medical equipment and drug supplies was defined as easily observable equipment important to women, such as the theatre for caesarean sections and incubators for premature babies. Women could easily determine availability of drugs at the health facility when they are sent outside of the hospital to buy 
Table 2 Example of a scenario in a choice set card that was presented to the women

The discrete choice experiment on attributes for place of delivery in rural subcounty in Kenya

Our objective is to conduct a DCE to explore the relative importance of attributes of place of delivery to Kenyan women living in Naivasha Sub-County to try and elucidate what women's values and their preferences are when they are making choices on place of delivery. You will be provided with a script on a mobile phone and you will be asked to imagine that you are pregnant and you are given a choice between the two health facilities to deliver your baby. Which one would you prefer? Facility A or facility B? You also have the option of choosing none of the two health facilities as option $\mathrm{C}$. There are no right or wrong answers.

\section{Sample choice card}

\begin{tabular}{llll} 
Attribute & Health facility A & Health facility B & Option C \\
Quality of clinical care during delivery & Good quality & Bad quality & (None of the two health \\
Attitude of healthcare workers & Kind and supportive attitude & Unkind attitude & facilities-home delivery) \\
Cost of delivery services & Ksh3000 & Ksh5000 \\
Availability of equipment and supplies & Equipment supplies not & Equipment and supplies \\
& available & available \\
Distance to health facility & Facility is close to home & Facility is far from home \\
Availability of referral health services & Referral services available & Referral services \\
Your choice (tick only one) & & unavailable & \\
\hline
\end{tabular}

DCE, discrete choice experiment.

essential drugs. Knowledge on both these attributes was also determined by conversations with other women from their social network. The availability of referral services was defined as the availability of a means of emergency referral transport to move the women from primary to tertiary level of care that could handle obstetric complications. The final DCE scenario with the final attributes can be seen in table 2 .

These questions were then loaded into Open Data Kit (ODK) and incorporated into a questionnaire consisting of items on sociodemographic and maternal health utilisation variables. The questionnaire contained questions adapted from the Kenya Demographic Health Survey 2014. See online supplemental appendix 3.

To obtain the sample size for the DCE, we used the rule by Johnson and Orme ${ }^{27}$ to suggest the sample size required for main effects. This depended on the number of choice tasks ( $\mathrm{t}$ ), the number of alternatives (a) and the number of analysis cells (c). We had 16 choice tasks (t) with 3 alternatives (a) and $3 * 2$ analysis cells (c). $\mathrm{N}>500 * \mathrm{c} / \mathrm{t} * \mathrm{a}=\mathrm{N}>500 * 6 / 16 * 3=\mathrm{N}>62.5 .{ }^{28}$ Using this formula, we derived a minimum sample size of 62.5 . We however collected a larger random sample of 474 women that would enable appropriate estimation of both main and interaction effects for the DCE. Our eventual targeted sample size was 474 from six health facilities to satisfy the representativeness for the quantitative survey for the sociodemographic variables but also large enough power to provide results that were statistically significant for all relevant attributes. Lancsar and Louviere ${ }^{29}$ in an earlier study recommend a sample of 20 respondents per questionnaire version as sufficient to estimate reliable DCE models. ${ }^{29}$

\section{Data collection}

A team of six research assistants along with their two supervisors received five trainings on data collection by the first author. Women were randomly recruited during postpartum immunisation clinics from a mix of six public and private health facilities. We randomly sampled 474 women. After the women gave informed consent, we then interviewed them using the ODK platform.

\section{Patient and public involvement}

During the pilot phases the women aged between 18 and 49 who were the main respondents provided feedback on the survey instruments. They also provided feedback during the qualitative phase on the selection of the attributes.

\section{Model specification}

The data were analysed in Stata V.15 (StataCorp, College Station, USA). Descriptive statistics were calculated for the non-DCE variables. The DCE data were analysed using the random utility model. ${ }^{30}$ This framework assumes that women seek to maximise their utility according to the perceived benefit associated with the different attributes and attribute levels. A model that expresses the utility ' $U$ ' of an alternative $i$ in a choice set $C_{n}$ (perceived by individual $n$ ) is shown in two parts: (1) an explainable component specified as a function of the attributes of the alternatives $V\left(X_{i n}, \beta\right)$; and (2) an unexplainable component (random variation) $\varepsilon_{i n}$.

$$
U_{i n}=V\left(X_{i n}, \beta\right)+{ }_{i n}
$$

The individual $n$ will choose alternative $i$ over other alternatives in a choice set $\mathrm{C}$ if and only if this alternative gives the maximised utility. The relationship between the utility function and the observed $k$ attributes of the 
alternatives can be assumed under a linear-in-parameter function. ${ }^{19}$ Therefore, the utility of the respondents attached is related to the attributes and attribute levels within the choice sets, meaning that if alternative $i$ is chosen within a choice set, $i$ will yield the maximum utility compared with $j$ alternatives. A is the alternative specific constant (ASC), $x$ are the attributes in the DCE and $\beta$ are the coefficients describing the marginal utility of the attribute. The standard conditional logit model is shown below:

$$
\mathrm{V}_{\mathrm{in}}=\alpha_{\mathrm{i}}+\beta_{\mathrm{i}} \mathrm{x}_{\mathrm{i} 1}++\beta_{\mathrm{k}} \mathrm{x}_{\mathrm{i}+\mathrm{e}}
$$

A base conditional model was used to estimate the mean change in utility, a preference which the respondent placed on attributes. $\alpha_{i}$ is a constant term that represents the general preference for place of delivery at a health facility compared with the alternative of opting out and having a home delivery. The reference group was the choice of health facility A or health facility B. Dummy coding was used for the data, each categorical attribute level was assigned a value of 1 whenever it was retained and 0 when omitted. The cost variable was maintained as a continuous variable. The utility model makes the assumption that women will trade off between the different attribute levels and choose the alternative that gives the greatest utility. The conditional model is suitable for estimating average preferences across respondents. The utility function was estimated for the following model:

$U_{i}=\alpha_{i}+\beta 1$ QualityClinicalcare $+\beta 2$ attitudeofhealthworkers +

$$
\begin{aligned}
& \beta 3 \text { Medicalequipmentandsupplies }+\beta 4 \text { distance } \\
& +\beta 5 \text { referral services }+\beta 6 \text { Costs }+\varepsilon(\text { error term })
\end{aligned}
$$

$\alpha_{i}$ is the ASC term that shows the preference for place of delivery (either a health facility or home), $\beta 1-\beta 6$ are the parameters for each of the attribute levels and $\varepsilon$ is the error term.

\section{Data analysis and model estimation}

The aim of the base multinomial logit model estimation is to determine whether the attributes are important (statistically significant, as shown by the significance level of the $\beta$ ) and the direction of importance (shown by the sign of the estimated $(\beta)$ and relative importance (size of the estimated parameter)). The main hypothesis test was whether the parameter estimates were significantly different from zero for all attributes.

Due to the assumption of irrelevant independent alternatives, the presence of heterogeneity in choices, we estimated a generalised mixed multinomial logit model to assess for preference heterogeneity among the women. ${ }^{31}$ The mixed multinomial logit model overcomes some of the limitations of the base multinomial logit by allowing for random taste variation, unrestricted substitution patterns and correlation in unobserved factors over time. The mixed multinomial logit can also use any distribution for the random coefficients. ${ }^{31}$ The five variables that described the attributes of place of delivery in the utility model above were entered into the model as random parameters whereas the cost variable was entered as a fixed variable. The mixed multinomial logit model allows for the estimation of both main and interaction effects. This was done by extending the mixed multinomial model and testing interactions between the sociodemographic and the women's attributes in order to investigate how preferences may vary according to observed individual characteristics. The sociodemographic characteristics included, such as maternal age, marital status, education and income status, have been known to influence place of delivery in Kenya. ${ }^{32-35}$ Education was measured in three categories: primary, secondary and tertiary education. We formed two dummy variables s1 and s2 representing a comparison between primary and secondary education to tertiary education. We categorised age into three categories: 18-24, 25-34 and 35-45 years. We then formed two dummy variables a1 and a2 to represent the first two age categories. Marital status and main earner had one dummy variable each that were interacted with the attributes.

The output of the mixed multinomial logit model includes the mean parameter estimate that represents the relative utility of each attribute. The SDs for a random parameter suggest the existence of heterogeneity in the parameter estimates over the sampled population around the mean parameter estimate, that is, different individuals possess individual-specific parameter estimates that may be different from the sample population mean parameter estimates. The $\mathrm{p}$ value of the interactions shows statistical significance for an interaction between sociodemographic variables and attributes, hence signifying the influence of the woman's characteristics. The robust SEs show the level of error. The theoretical validity of the design will be explored by examining the signs and significance levels of parameter estimates. To address bias, we tested for choice monotonicity; this is the assumption that a respondent will choose an alternative in the choice task that is superior to the other alternatives on all choice attributes. ${ }^{29}$

\section{RESULTS}

\section{Participant characteristics}

Four hundred and seventy-four women were invited to participate in the DCE. There were incomplete data for eight respondents. The DCE survey was successfully administered to 466 representing a $98 \%$ response rate. The average age of the respondents was 26 years, $32 \%$ were primiparous. Eighty-eight per cent of the women reported themselves as married and $48 \%$ had attained a secondary school education. About $53 \%$ of the heads of household had attained up to a secondary education. Only $18 \%$ of the rural women were heads of household; however, $95 \%$ respectively claimed to have influence over household-level decisions. Approximately 83\% reported that they were not the main source of household income. Finally, about $67 \%$ of the women reported having moved to the study setting from elsewhere within the last 
Table 3 Sociodemographic characteristics of women in Naivasha Sub-County $(n=466)$

\begin{tabular}{lc}
\hline & Naivasha Sub-County \\
\cline { 2 - 2 } Sociodemographic variables & $\mathbf{n}(\%)$ \\
\hline Age, $\mathrm{n}$ (mean (SD)) & $26(5.1)$ \\
\hline Marital status & $57(12)$ \\
\hline Single & $409(88)$ \\
\hline Married & \\
\hline Education & $175(38)$ \\
\hline Primary school & $221(48)$ \\
\hline Secondary school & $66(14)$ \\
\hline University/tertiary & $151(32)$ \\
\hline Parity & $215(68)$ \\
\hline 1 & \\
\hline$\geq 2$ & $381(82)$ \\
\hline Head of household status & $85(18)$ \\
\hline Woman not HH & \\
\hline Woman head of HH & $100(27)$ \\
\hline Head of household education & $196(53)$ \\
\hline Primary school & $72(20)$ \\
\hline Secondary school \\
\hline University/tertiary \\
\hline Woman's influence on decision-making within HH \\
\hline Woman had no influence & $18(5)$ \\
\hline Woman had influence & $363(95)$ \\
\hline Main earner status & \\
\hline Is not the main earner & $386(83)$ \\
\hline Is the main earner & $79(17)$ \\
\hline Residence (moves) & $29(6)$ \\
\hline Moved in 5 years & $112(33)$ \\
\hline Moved over 5 years & \\
\hline Delivery health facility & \\
\hline Public facility & \\
\hline Private facility & $(19)$ \\
\hline Home delivery & \\
\hline
\end{tabular}

$\mathrm{HH}$, household.

5 years. See table 3 for details on the sociodemographic characteristics.

To enable the estimation of main and interaction effects, each respondent was given a survey with three unlabelled alternatives (health facility A, health facility $\mathrm{B}$ and an opt-out option) with 16 choice sets to choose from, resulting into 48 observations per respondent. The number of observations analysed within the rural site was 22368 out of 22566 . One hundred and ninetyeight observations were dropped by STATA automatically because of dominant choices.
In the rural setting, the variable with the greatest association with choice of health facility was attitude of the healthcare workers, followed by availability of medical equipment and drugs, and third, the quality of clinical services during delivery, the distance to the health facility, availability of referral health facility; cost of delivery was ranked fourth, fifth and sixth $(p<0.001)$. The opt-out alternative had a negative sign and was ranked seventh $(\mathrm{p}<0.001)$. See table 4 .

The direction of the coefficient signs provides a check on the theoretical validity of the DCE model, that is, whether the coefficients move as economic theory or a priori expectation would predict. All the attributes with the exception of the opt-out had the expected positive signs. The cost attribute was positive; however, economic theory expects them to be negative showing that women have a disutility for high costs.

For the mixed multinomial logit model with no interactions, we found out that all the mean coefficient values for all the attributes were statistically significant at the $99 \%$ level $(p<0.0001)$, with the exception of the optout attribute $(\mathrm{p}=0.377)$. See table 5 . This meant that we could reject the null hypothesis and conclude that all the selected attributes selected were important to the female respondents. The low significance value for the opt-out suggested that women had a low value for home deliveries. All the attributes had strong statistically significant parameter estimates for the SD, except the cost attribute which had significance at the $90 \%$ level $(\mathrm{p}=0.639)$. This suggested weak preference heterogeneity, meaning that was very little variation around the mean, with very few women who possessed individual-specific parameter estimates that might be different from the sample population mean. On analysing the differences between primiparous and multiparous women with regard to choosing the optout, we found that women who were multiparous were more likely to choose the opt-out, suggesting a dissatisfaction with their experience at the health facility.

\section{Preference heterogeneity}

The influence of sociodemographic characteristics on the preferences suggested variation in preferences for the attributes for place of delivery. See table 6. For the mean parameters, women with a secondary education had a moderate strong preference for quality of clinical care $(\mathrm{p}=0.012)$. Women aged between 25 and 34 years had a moderately strong preference for good clinical quality $(\mathrm{p}=0.034)$ and a short distance to the health facility $(p=0.024)$. Married women had a moderate preference for a health facility with available medical equipment and drugs $(p=0.004)$ and a weak preference for a short distance to the health facility $(p=0.085)$. Women who were main earners had a moderate strong preference for availability of referral services at a health facility $(\mathrm{p}=0.009)$, a short distance to the health facility $(\mathrm{p}=0.045)$ and a cost of delivery services $(\mathrm{p}=0.035)$.

The SD shows the variation around the mean, parameters showing heterogeneity in the preferences among 
Table 4 The base multinomial logit model for a DCE on preferences for place of delivery among women in a rural subcounty

\begin{tabular}{|c|c|c|c|}
\hline \multirow[b]{2}{*}{ Attribute } & \multicolumn{3}{|c|}{ Rural subcounty } \\
\hline & $\beta$ & Robust SE & $95 \% \mathrm{Cl}$ \\
\hline $\begin{array}{l}\text { Attitude } \\
\text { Kind (Reference) }\end{array}$ & $1.184^{\star \star \star}$ & 0.037 & 1.11 to 1.25 \\
\hline $\begin{array}{l}\text { Medequip } \\
\text { Available (Reference) }\end{array}$ & $1.073^{\star \star \star}$ & $<0.035$ & 1.01 to 1.13 \\
\hline $\begin{array}{l}\text { Qualclin } \\
\text { Good (Reference) }\end{array}$ & $0.826^{\star * *}$ & 0.034 & 0.76 to 0.89 \\
\hline $\begin{array}{l}\text { Distance } \\
\text { Short (Reference) }\end{array}$ & $0.457^{\star \star \star}$ & 0.031 & 0.39 to 0.52 \\
\hline $\begin{array}{l}\text { Referral } \\
\text { Available (Reference) }\end{array}$ & $0.266^{\star \star \star}$ & 0.033 & 0.20 to 0.33 \\
\hline Costs & $0.000018^{\star \star \star}$ & $9.40 e-06$ & $2.55 \mathrm{e}-06$ to 0.00033 \\
\hline
\end{tabular}

Attitude: attitude of healthcare workers. Distance: distance to health facility. Referral: referral service availability. Clean: cleanliness of the health facility.

${ }^{*}$ Significance at the $90 \%$ level; **Significance at the 95\% level; ${ }^{* *}$ Significance at the $99 \%$ level.

ASC, alternative specific constant; DCE, discrete choice experiment; Medequip, medical equipment and drugs; Qualclin, quality of the clinical delivery services.

the women. There was a strong variation in preferences for the three attributes: availability of medical equipment and drugs $(\mathrm{p}<0.0001)$, good quality clinical care $(\mathrm{p}<0.0001)$ and the availability of referral services at the health facility $(\mathrm{p}<0.0001)$ among women with secondary education. This finding suggests that several women in this category possessed individual-specific parameter estimates that are different from the sample population mean for the attributes. Women who were aged between 25 and 34 years showed strong preference heterogeneity for the attributes on kind and supportive health worker $(\mathrm{p}=0.001)$, availability of medical equipment and drug supplies $(\mathrm{p}<0.0001)$ and good quality clinical care $(p<0.0001)$. Married women showed strong preference

Table 5 The mixed multinomial logit model showing means and SDs to explain preference heterogeneity in choices made by women in rural setting

\begin{tabular}{|c|c|c|c|c|}
\hline \multirow[b]{2}{*}{ Attribute } & \multicolumn{2}{|c|}{ Mean coefficient values } & \multicolumn{2}{|l|}{ SD } \\
\hline & $\beta$ & Robust SE & $\beta$ & Robust SE \\
\hline $\begin{array}{l}\text { Attitude } \\
\text { Kind (Reference) }\end{array}$ & $1.972^{* \star *}$ & 0.123 & $1.582^{\star \star \star}$ & 0.108 \\
\hline $\begin{array}{l}\text { Medequip } \\
\text { Available (Reference) }\end{array}$ & $1.764^{\star \star \star}$ & 0.076 & $0.778^{\star \star \star}$ & 0.702 \\
\hline $\begin{array}{l}\text { Qualclin } \\
\text { Good (Reference) }\end{array}$ & $1.316^{\star \star \star}$ & 0.106 & $1.577^{\star \star \star}$ & 0.126 \\
\hline $\begin{array}{l}\text { Distance } \\
\text { Short (Reference) }\end{array}$ & $0.759^{* \star *}$ & 0.052 & $0.374^{\star * \star}$ & 0.091 \\
\hline $\begin{array}{l}\text { Referral services } \\
\text { Available (Reference) }\end{array}$ & $0.436^{\star \star \star}$ & 0.054 & $0.535^{\star \star \star}$ & 0.085 \\
\hline ASC & $0.289^{\star}$ & 0.327 & $3.202^{\star \star \star}$ & 0.179 \\
\hline Prob $>\chi^{2}$ & 0.0000 & & & \\
\hline Log likelihood & -4400.9 & & & \\
\hline
\end{tabular}

Attitude: attitude of healthcare workers. Distance: distance to the health facilities.

${ }^{*}$ Significance at the $90 \%$ level; ${ }^{*}$ Significance at the $95 \%$ level; ${ }^{* \star *}$ Significance at the $99 \%$ level.

ASC, alternative specific constant; Medequip, medical equipment and drugs; Qualclin, quality of clinical services. 


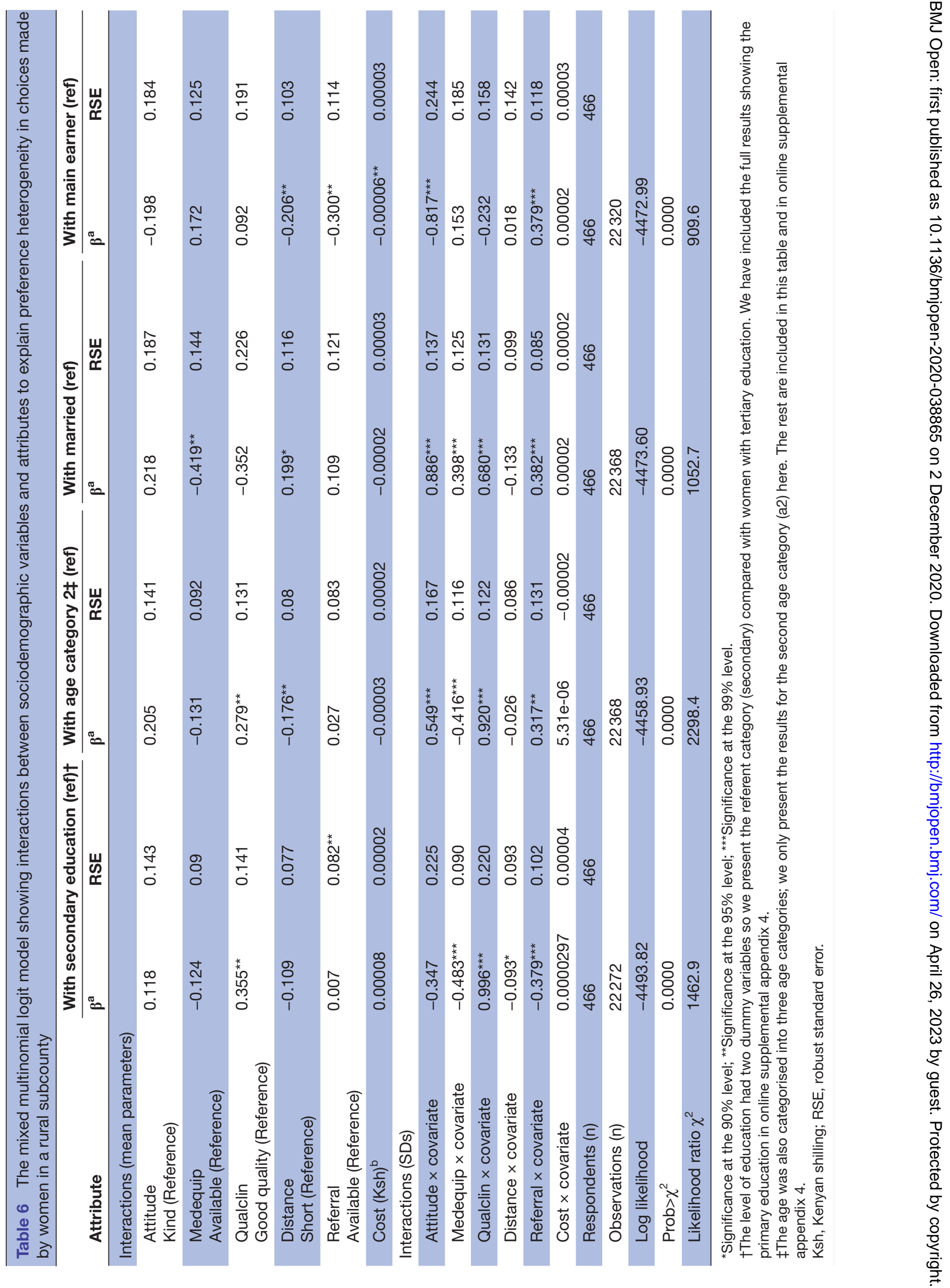


heterogeneity for four attributes: kind and supportive attitude of healthcare workers $(\mathrm{p}<0.0001)$, availability of medical equipment and drug supplies $(\mathrm{p}=0.001)$, good quality clinical care $(\mathrm{p}<0.0001)$ and the availability of referral services at the health facility $(p<0.0001)$. Lastly, women who reported themselves as main earners showed strong preference heterogeneity for the attributes of kind and supportive attitude of healthcare workers $(\mathrm{p}=0.001)$ and availability of referral services only $(\mathrm{p}=0.001)$.

All women across the four sociodemographic groups showed no variation for the attribute of costs of delivery and distance to the delivery health facility with the exception of women with secondary education $(\mathrm{p}<0.0001)$, suggesting that there was no variation in the individual characteristics of women who valued these two attributes

\section{DISCUSSION}

This study explored women's preferences for characteristics for delivery health facilities in a rural subcounty in Kenya. The most highly valued attribute for women when making a choice of a delivery facility was the attitude of healthcare workers; this was followed by the availability of medical equipment and quality of clinical services. Lowly valued attributes were the availability of referral services and the cost of delivery service. The opt-out alternative that signified home delivery was ranked last and was negative signifies women had a disutility for home deliveries in this setting. All the attributes had an impact on the probability of choosing a health facility for delivery over a home delivery. To the best of our knowledge, this is the first DCE to address attributes valued by women in a rural setting in Kenya within the context of a free maternity services policy.

We found out that the attitude of healthcare workers providing delivery services was valued above all other attributes. Quality of care standards require that women be treated in a respectful manner and in a way that upholds their dignity. ${ }^{17}$ Recent evidence has identified that the attitude of health workers during labour and delivery presents a huge challenge with reports of mistreatment of women. ${ }^{36}$ This has also been reported in diverse settings within sub-Saharan African such as Guinea, ${ }^{37}$ Nigeria $^{38}$ and South Africa. ${ }^{39}$ The high value for attitude of healthcare workers has been reflected in other DCE studies in rural settings in sub-Saharan Africa. ${ }^{21} 40$ Mistreatment has increasingly been recognised as a barrier to women accessing facility-based delivery in Kenya across contexts with one study placing prevalence of disrespect and abuse at 20\%. ${ }^{41}$ Urgent international calls have been made for accountability for the mistreatment of women during labour and delivery because it is a compelling human rights issue. ${ }^{42}{ }^{43}$ Mistreatment should be addressed during regular supervision in all facilities to ensure a functioning feedback mechanism for respectful care during delivery. ${ }^{44}$

The second most valued attribute was the availability of medical equipment and drug supplies at the health facility. These were easily observable aspects of the health facilities that women saw during their antenatal care (ANC) visits and identifying the availability of theatres for caesarean sections and neonatal resuscitation equipment. They were also informed by friends and family who had prior visits to the health facilities. Studies evaluating the state of obstetric care coverage often compare the provision of care to the physical infrastructure available without assessing the care provided at health facilities. For example, a recent study that evaluated emergency obstetric care (EMOC) services across health facilities in rural Kenya found that EMOC capabilities were not being met and confirmed that only two of the five health centres assessed had acceptable EMOC capabilities illustrating the state of rural health facilities for obstetric care. ${ }^{45}$ Additionally, recent assessments of quality of care at Kenyan health facilities have shown that medical equipment and drug supplies for mothers were only available at $41 \%$ of health facilities (both public and private). ${ }^{15}$ Health policymakers need to focus on availing EMOC capabilities because women's preferences suggest that they value the availability of equipment as a way of judging the quality of care at a health facility.

The women showed a high preference for quality of clinical care and ranked it third. One study focused on attributes of respectful care ranked women's preference for good health system conditions such as having a qualified birth attendant among other conditions. ${ }^{46}$ This suggests that women can ascertain to a certain degree of the quality of care is from assessing their delivery experience including the necessity of caesarean sections. This calls for skilled birth attendants to provide better quality clinical care that is based on WHO evidence-based guidelines. ${ }^{17}$

Referral availability at the health facility was defined as transportation of women from the health facility where they first sought care to a higher level health facility in the case of complications. Though ranked lower by women, this attribute was still valued. This finding suggests that referral options at health facilities in this setting are weak. Women mentioned that they were afraid of developing complications because of the unavailability of ambulances at the lower level health facilities. WHO standards advocate for referrals that are conducted in a timely fashion with a pre-established plan for delivery care and with relevant sharing of information between the concerned staff at the receiving health facilities. ${ }^{17}$

An unexpected finding was the disutility for lower costs. This finding suggests that the women had a value for paying higher amounts of money for better quality of delivery services. We hypothesise that the women were making a trade-off by selecting higher amounts and signalling that they were willing to pay higher amounts for obtaining services that they perceived as being of higher quality. This finding is critical given that approximately half of all women (55\%) in this setting had access to any health insurance coverage of any type. This implies that the women would use out-of-pocket payments at private health facilities. Such payments have been associated with 
putting patients at significant financial risk. Additional evidence points out challenges with the free maternity services with women reporting paying for key birthing items including pharmaceuticals. ${ }^{47} 48$ The women also described public health facilities advertised as 'free', but were exposed to hidden informal indirect costs during billing. Costs, both direct and indirect, have been previously identified in studies assessing factors influencing place of delivery in Kenya. ${ }^{49} 50$

Our findings also indicate that multiparous women were more likely to choose a home delivery over primiparous women, suggesting some evidence of dissatisfactory experiences during delivery that would deter them from a repeat visit to the health facility. Recent studies in certain rural settings in Kenya suggest cultural values that promote home deliveries especially because of fear of health workers at health facilities. ${ }^{3351}$

In assessing how sociodemographics influence choice of attributes, we found that women with secondary education had a strong preference for clinical quality, suggesting that highly educated women in this setting were able to discern certain elements of clinical quality either through their own experiences during ANC or the experiences of other women in their social network. Other DCE studies also had similar findings suggesting changing demographics with rural areas having more educated women. ${ }^{22}$ We also discovered that younger women are more knowledgeable about the health system and might exercise their rights to demand better quality healthcare. Studies suggest that decisions on healthcare are done in a social context in consultation with their families and friends. ${ }^{52} 53$ There have been recent reports of young mothers in rural areas in Kenya receiving poor quality services at health facilities. ${ }^{54}$ Married women had more experiences with the health system from previous deliveries and were aware of expectations with regard to medical equipment and drugs. Lastly, women who were main earners had strong preferences for costs which was expected. Thus, targeting strategies specific to certain demographics within the population can help the health system be more responsive to women's needs.

The main strength of the study was that it was conducted within the context of the newly implemented free maternity services policy in Kenya. The findings of this study can inform the contextual aspects of quality of care valued by women. The main limitation of the study was the hypothetical nature of the DCE might result in bias. Respondents might make inaccurate choices while being aspirational regarding the quality of services they expect at a health facility during delivery. Hypothetical choices might not be representative of women's choices because decision-making around delivery place in real life may be made in a social context with other key family members involved especially in rural contexts.

The study sample were likely to be users of the health system and represent some positive bias towards the utilisation of health services. These findings might not generalise the findings to the minority of women who eschew health services-induced immunisation. In future, sampling of women who delivered at home might help assist with eliciting preferences of women who are not users of facility-based delivery services.

\section{CONCLUSION}

This study showed that women's experience of care during delivery, and attributes such as attitude of healthcare workers, availability of equipment and supplies, and access to good quality delivery care are highly valued by women and may affect the utilisation of health facilities during the free maternity services. The women's choices indicate their preferences for both structural and process aspects of quality of care. It is critical for policymakers to understand women's preferences and what drives them to seek delivery services at health facilities. Ensuring high-quality care that is patient centred can reduce inequities in maternal deaths and improve maternal health outcomes.

\section{Twitter Jackline Oluoch-Aridi @Jackie0A and Francis Wafula @frankfula}

Acknowledgements The authors would like to thank the County Government of Nakuru, and Naivasha Sub-County Director of Medical Services Dr Benedict Osore for giving us permission to conduct this study. We would also like to thank Cindy Makanga, Brian Ambutsi, Sandra Masira, Mercy Ngao, Hellen Wafula and Anne Ngichiri, research assistants for the data collection at the health facilities in Naivasha, We also thank Maurice Baraza, Sydney Oluoch and Melvin Obadha for their assistance with the data analysis. We thank Dr Ben Ngoye, Tecla Kivuli and Eric Tama for their feedback during PhD seminars. Lastly and most importantly, special thanks to the women and healthcare workers at the different health facilities within Naivasha for allowing us to interview them.

Contributors JOA and MBA conceptualised the study. JOA conducted the data analysis and drafted the manuscript. JOA, MBA, FW and GK revised the manuscript and provided critically important feedback on the manuscript. All authors read and approved the final manuscript.

Funding This work was supported by a grant from the Ford Family Program in Human Development Studies and Solidarity. Kellogg Institute of International Studies at the University of Notre Dame supports the first author in conducting the research (grant number 17-11-4218).

Competing interests None declared.

Patient consent for publication Not required.

Ethics approval Permission to conduct this research was provided by the National Commission for Science, Technology and Innovation (NACOSTI) through a research permit number P17/34367/2013, by the County Government of Nakuru and an institutional research ethical approval from AMREF ERSC (approval number P388/2017).

Provenance and peer review Not commissioned; externally peer reviewed.

Data availability statement The data sets used and analysed during the current study can be accessed via the Dryad data repository at http://datadryad.org/ with the doi: 10.5061/dryad.1vhhmgqrk.

Supplemental material This content has been supplied by the author(s). It has not been vetted by BMJ Publishing Group Limited (BMJ) and may not have been peer-reviewed. Any opinions or recommendations discussed are solely those of the author(s) and are not endorsed by BMJ. BMJ disclaims all liability and responsibility arising from any reliance placed on the content. Where the content includes any translated material, BMJ does not warrant the accuracy and reliability of the translations (including but not limited to local regulations, clinical guidelines, terminology, drug names and drug dosages), and is not responsible for any error and/or omissions arising from translation and adaptation or otherwise.

Open access This is an open access article distributed in accordance with the Creative Commons Attribution Non Commercial (CC BY-NC 4.0) license, which permits others to distribute, remix, adapt, build upon this work non-commercially, 
and license their derivative works on different terms, provided the original work is properly cited, appropriate credit is given, any changes made indicated, and the use is non-commercial. See: http://creativecommons.org/licenses/by-nc/4.0/.

\section{ORCID iD}

Jackline Oluoch-Aridi http://orcid.org/0000-0002-8456-6735

\section{REFERENCES}

1 WHO, UNICEF, UNFPA, BANK W, UN. Trends in maternal mortality 2000 to 2017: estimates by who, UNICEF, UNFPA, world bank group and the United nations population division. Geneva: World Health Organization, 2019.

2 Filippi V, Ronsmans C, Campbell OMR, et al. Maternal health in poor countries: the broader context and a call for action. Lancet 2006;368:1535-41.

3 Koblinsky M, Moyer CA, Calvert C, et al. Quality maternity care for every woman, everywhere: a call to action. Lancet 2016;388:2307-20.

4 Montagu D, Sudhinaraset M, Diamond-Smith N, et al. Where women go to deliver: understanding the changing landscape of childbirth in Africa and Asia. Health Policy Plan 2017;32:1146-52.

5 Doctor HV, Nkhana-Salimu S, Abdulsalam-Anibilowo M. Health facility delivery in sub-Saharan Africa: successes, challenges, and implications for the 2030 development agenda. BMC Public Health 2018;18.

6 National Bureau of Statistics, Ministry of Health/Kenya, National AIDS Control Council/Kenya, Kenya Medical Research Institute and NC for P and D. Kenya demographic health survey, 2015.

7 Bourbonnais N. Implementing free maternal health care in Kenya. 3. Kenya National Commission on Human Rights, 2013. http://www. knchr.org/Portals/O/EcosocReports/Implementing Free Maternal Health Care in Kenya.pdf

8 National Coordinating Agency for Population and Development (NCAPD) [Kenya], Ministry of Medical Services (MOMS) [Kenya], Ministry of Public Health and Sanitation (MOPHS) [Kenya], Kenya National Bureau of Statistics (KNBS) [Kenya], ICF Macro. Kenya Service Provision Assessment (SPA) 2010. Kenya Serv Provis Assess Surv [Internet], 2011: 1-695. https://esaro.unfpa.org/sites/default/ files/pub-pdf/Kenya Service Provision Assessment Survey 2010. pdf\%0Ahttp://dhsprogram.com/pubs/pdf/SPA17/SPA17.pdf

9 UNFPA. Summary report of the assessment of UNFPA' S advocacy campaign to end preventable maternal and new-born mortality in Kenya list of abbreviations; 2014.

10 Arsenault C, English M, Gathara D, et al. Variation in competent and respectful delivery care in Kenya and Malawi: a retrospective analysis of national facility surveys. Trop Med Int Heal 2019;00:1-12.

11 Njuguna J, Kamau N, Muruka C. Impact of free delivery policy on utilization of maternal health services in County referral hospitals in Kenya. BMC Health Serv Res 2017;17:1-6.

12 Sharma J, Leslie HH, Kundu F, et al. Poor quality for poor women? inequities in the quality of antenatal and delivery care in Kenya. PLoS One 2017;12:e0171236-14.

13 Afulani PA, Sayi TS, Montagu D. Predictors of person-centered maternity care: the role of socioeconomic status, empowerment, and facility type. BMC Health Serv Res 2018;18:1-16.

14 Kruk ME, Leslie HH, Verguet S, et al. Quality of basic maternal care functions in health facilities of five African countries: an analysis of national health system surveys. Lancet Glob Health 2016;4:e845-55.

15 Chen A, Dutta A, Maina T. Assessing the quality of primary healthcare services in Kenya. Evidence from the PETS-plus survey 2014, 2014

16 Ministry of Health. Kenya quality model for health empowering health workers to improve service delivery. Facilitator's Manual, 2014: 1-92.

17 WHO. Standards for improving quality of maternal and newborn care in health facilities. 73. World Health Organisation, 2016. http://www. who.int/iris/handle/10665/249155

18 Ryan M, Gerard K. Using discrete choice experiments to value health care programmes: current practice and future research reflections. In: Applied health economics and health policy. , 2003: 2, 55-64.

19 Louviere JJ, Pihlens D, Carson R. Design of discrete choice experiments: a discussion of issues that matter in future applied research. Journal of Choice Modelling 2011;4:1-8.

20 Honda A, Ryan M, van Niekerk R, et al. Improving the public health sector in South Africa: eliciting public preferences using a discrete choice experiment. Health Policy Plan 2015;30:600-11.

21 Kruk ME, Paczkowski M, Mbaruku G, et al. Women's preferences for place of delivery in rural Tanzania: a population-based discrete choice experiment. Am J Public Health 2009;99:1666-72.

22 Larson E, Vail D, Mbaruku GM, et al. Moving toward patientcentered care in Africa: a discrete choice experiment of preferences for delivery care among 3,003 Tanzanian women. PLoS One 2015;10:e0135621-12

23 Coast J, Al-Janabi H, Sutton EJ, et al. Using qualitative methods for attribute development for discrete choice experiments: issues and recommendations. Health Econ 2012;21:730-41.10.1002/hec.1739

24 de Bekker-Grob EW, Ryan M, Gerard K. Discrete choice experiments in health economics: a review of the literature. Health Econ 2012;21:145-72.

25 ChoiceMetrics. Ngene 1.2 USER MANUAL \& REFERENCE GUIDE The Cutting Edge in Experimental Design End-User License Agreement, 2018. Available: www.choice-metrics.com

26 Huber J, Zwerina K. The importance of utility balance in efficient choice designs. J Market Res 1996;33:307-17.

27 Johnson RM, Orme BK. Getting the most from CBC. sawtooth software research paper. Sequim: Sawtooth Software, 2003.

28 Orme BK. Sample size issues for conjoint analysis. In: Getting started with conjoint analysis: strategies for product design and pricing research. Madison, Wis: Research Publishers LLC, 2010: 57-66. https://www.sawtoothsoftware.com/download/techpap/samplesz. pdf

29 Lancsar E, Louviere J. Deleting 'irrational' responses from discrete choice experiments: a case of investigating or imposing preferences? Health Econ 2006;15:797-811.

30 McFadden D. Conditional Logit analysis of qualitative choice behaviour. Front Econom 1974

31 Louviere JJ, Hensher DA, Swait JD. Stated choice methods : analysis and applications. Cambridge University Press, 2000: 402.

32 Gitimu A, Herr C, Oruko H, et al. Determinants of use of skilled birth attendant at delivery in Makueni, Kenya: a cross sectional study. BMC Pregnancy Childbirth 2015;15.

33 Karanja S, Gichuki R, Igunza P, et al. Factors influencing deliveries at health facilities in a rural Maasai community in Magadi sub-County, Kenya. BMC Pregnancy Childbirth 2018;18:1-11.

34 Wanjira C, Mwangi M, Mathenge E, et al. Delivery practices and associated factors among mothers seeking child welfare services in selected health facilities in Nyandarua South district, Kenya. BMC Public Health 2011;11.

35 Kitui J, Lewis S, Davey G. Factors influencing place of delivery for women in Kenya: an analysis of the Kenya demographic and health survey, 2008/2009. BMC Pregnancy Childbirth 2013;13:1.

36 Bohren MA, Hunter EC, Munthe-Kaas HM, et al. Facilitators and barriers to facility-based delivery in low- and middle-income countries: a qualitative evidence synthesis. Reprod Health 2014;11:1-17.

37 Balde MD, Diallo BA, Bangoura A, et al. Perceptions and experiences of the mistreatment of women during childbirth in health facilities in guinea: a qualitative study with women and service providers. Reprod Health 2017;14:1-13.

38 Bohren MA, Vogel JP, Tunçalp Özge, et al. Mistreatment of women during childbirth in Abuja, Nigeria: a qualitative study on perceptions and experiences of women and healthcare providers. Reprod Health 2017;14:1-13.

39 Jewkes R, Abrahams N, Mvo Z. Why do nurses abuse patients? reflections from South African obstetric services. Soc Sci Med 1998;47:1781-95.

40 Hanson K, McPake B, Nakamba P, et al. Preferences for hospital quality in Zambia: results from a discrete choice experiment. Health Econ 2005;14:687-701.

41 Abuya T, Warren CE, Miller N, et al. Exploring the prevalence of disrespect and abuse during childbirth in Kenya. PLoS One 2015;10:e0123606.

42 Jewkes R, Penn-Kekana L. Mistreatment of women in childbirth: time for action on this important dimension of violence against women. PLoS Med 2015;12:e1001849.

43 Afulani PA, Moyer CA. Accountability for respectful maternity care. Lancet 2019;394:1692-3.

44 Warren CE, Njue R, Ndwiga C, et al. Manifestations and drivers of mistreatment of women during childbirth in Kenya: implications for measurement and developing interventions. BMC Pregnancy Childbirth 2017:17:1-14.

45 Echoka E, Makokha A, Dubourg D, et al. Barriers to emergency obstetric care services: accounts of survivors of life threatening obstetric complications in Malindi district, Kenya. Pan Afr Med J 2014;17:4.

46 Umar N, Quaife M, Exley J, et al. Toward improving respectful maternity care: a discrete choice experiment with rural women in northeast Nigeria. BMJ Glob Health 2020;5:e002135.

47 Lang'at E, Mwanri L. Healthcare service providers' and facility administrators' perspectives of the free maternal healthcare services policy in Malindi District, Kenya: A qualitative study. Reprod Health 2015;12:1-11. 
48 Tama E, Molyneux S, Waweru E, et al. Examining the implementation of the free maternity services policy in Kenya: a mixed methods process evaluation. Int $J$ Health Policy Manag 2018;7:603-13.

49 Kinuthia J, Kohler P, Okanda J, et al. A community-based assessment of correlates of facility delivery among HIV-infected women in Western Kenya. BMC Pregnancy Childbirth 2015;15:1-9.

50 Chuma J, Maina T. Catastrophic health care spending and impoverishment in Kenya. BMC Health Serv Res 2012;12:413.

51 Naanyu V, Baliddawa J, Koech B, et al. "Childbirth is not a Sickness; A Woman Should Struggle to Give Birth": Exploring Continuing
Popularity of Home Births in Western Kenya. Afr J Reprod Health 2018;22:85-93.

52 Moyer CA, Adongo PB, Aborigo RA, et al. "It's up to the woman's people": how social factors influence facility-based delivery in Rural Northern Ghana. Matern Child Health J 2014;18:109-19.

53 Naanyu V, Mujumdar V, Ahearn C, et al. Why do women deliver where they had not planned to go? A qualitative study from peri-urban Nairobi Kenya. BMC Pregnancy Childbirth 2020;20:1-9.

54 Lusambili AM, Naanyu V, Wade TJ, et al. Deliver on your own: Disrespectful maternity care in rural Kenya. PLoS One 2020;15:e0214836-16. 